\title{
The maximum chemiluminescence intensity predicts severe neutropenia in gemcitabine-treated patients with pancreatic or biliary tract cancer
}

\author{
Koki Goto ${ }^{1} \cdot$ Ryusei Matsuyama ${ }^{1} \cdot$ Yusuke Suwa ${ }^{1} \cdot$ Sayaka Arisaka ${ }^{1} \cdot$ Toshiaki Kadokura $^{1} \cdot$ Mari Sato $^{1} \cdot$ Ryutaro Mori $^{1}$. \\ Takafumi Kumamoto $^{1} \cdot$ Masataka Taguri $^{2} \cdot$ Itaru Endo $^{1}$
}

Received: 10 August 2018 / Accepted: 5 September 2018 / Published online: 14 September 2018

(c) The Author(s) 2018

\begin{abstract}
Purpose To assess the predictive ability of the maximum chemiluminescence intensity $\left(\mathrm{CI}_{\max }\right)$ for severe neutropenia $(\mathrm{SN})$ during neoadjuvant chemo(radio)therapy [NAC(RT)] in patients with advanced pancreatic or biliary tract cancer.

Methods Clinicopathological variables and blood test data before NAC(RT) were evaluated in 64 patients with advanced pancreatic or biliary tract cancer who received gemcitabine plus tegafur/gimeracil/oteracil as NAC(RT).

Results Thirty-nine patients (60.9\%) developed Grade 3-4 SN. The median time between commencing NAC(RT) and the onset of SN was 15 (range 10-36) days. SN occurred during the NAC period, not the RT period. The $\mathrm{CI}_{\text {max }}$, neutrophil count, serum interleukin-6 level, C-reactive protein level, complement $\mathrm{C} 3$ titer, serum complement titer, and $50.0 \%$ hemolytic unit of complement before NAC(RT) were significantly lower in patients with SN than in those without $\mathrm{SN}(P<0.05)$. Multivariate analysis confirmed the $\mathrm{CI}_{\max }$ to be the sole independent predictor of SN $(P<0.05)$. The optimal threshold for the $\mathrm{CI}_{\max }$ was $46,000 \mathrm{RLU} / \mathrm{s}$. The sensitivity and specificity were $46.2 \%$ and $80.0 \%$, respectively. Majority of the patients $(81.8 \%)$ with a low $\mathrm{CI}_{\max }$ before $\mathrm{NAC}(\mathrm{RT})$ experienced $\mathrm{SN}$ during $\mathrm{NAC}(\mathrm{RT})$.

Conclusions $\mathrm{CI}_{\max }$ before NAC(RT) predicts $\mathrm{SN}$ during $\mathrm{NAC}(\mathrm{RT})$ in patients with advanced pancreatic or biliary tract cancer.
\end{abstract}

Keywords Biliary tract cancer $\cdot$ Chemiluminescence $\cdot$ Gencitabine $\cdot$ Neoadjuvant chemotherapy $\cdot$ Neutropenia $\cdot$ Pancreatic cancer

\section{Introduction}

Majority of the patients with advanced pancreatic or biliary tract cancer have a poor prognosis. Complete surgical resection is currently the only potentially curative treatment for long-term survival. However, majority of the patients considered to have localized cancer by radiographic examination actually have undetected systemic disease and are unlikely to benefit from surgical treatment alone $[1,2]$. However, with rapid developments in chemotherapeutic

Itaru Endo

endoit@yokohama-cu.ac.jp

1 Department of Gastroenterological Surgery, Yokohama City University Graduate School of Medicine, 3-9 Fukuura, Kanazawa-ku, Yokohama 236-0004, Japan

2 Department of Biostastics and Epidemiology, Yokohama City University Graduate School of Medicine, Yokohama, Japan regimens, both adjuvant chemotherapy and neoadjuvant chemo(radio)therapy (NAC(RT)) have been shown to be beneficial for patients with borderline resectable pancreatic cancer [3] or advanced biliary tract cancer [4]. While gemcitabine plus tegafur/gimeracil/oteracil (GS) as NAC(RT) has been reported to be safe and effective for patients with borderline resectable pancreatic cancer [5], GS as adjuvant chemotherapy [6] and gemcitabine as NAC [7] have been reported to be safe and effective for patients with advanced biliary tract cancer.

We have performed NAC(RT)-GS in patients with advanced pancreatic or biliary tract cancer. Bone marrow suppression, an adverse effect of anticancer drugs, was frequently observed in patients treated with NAC(RT)GS. The incidence of severe neutropenia (SN) [Grade $\geq 3$ according to the Common Terminology Criteria for Adverse Events (version 4.0) [8]] was particularly high and has been reported in approximately $62.2 \%$ of patients [9]. $\mathrm{SN}$ is a major toxicity that forces a reduction in the relative dose 
intensity (RDI) of the anticancer drugs used in NAC(RT). SN during NAC(RT) can also complicate tumor resection. However, the risk of SN during gemcitabine-based therapy has not been extensively studied.

Previous studies have demonstrated that risk factors for SN and febrile neutropenia include old age [10, 11], female sex [12], a poor Eastern Cooperative Oncology Group performance status [13], a low body mass index [14], a small body surface area [15], a history of cardiovascular disease [10], diabetes mellitus [16], a poor nutritional status, inflammation [11, 13], and a low baseline absolute neutrophil count (ANC) [17]. Kiguchi et al. [18] reported that the maximum chemiluminescence intensity $\left(\mathrm{CI}_{\max }\right)$, as assessed by an in vitro reaction between peripheral neutrophils and endotoxin, is indicative of the maximum neutrophil activity in whole blood. A low $\mathrm{CI}_{\max }$ is also associated with the exhaustion of peripheral polymorphonuclear leukocytes. $\mathrm{CI}_{\max }$ has been suggested to be predictive of mortality in patients with sepsis. Therefore, in addition to the baseline ANC, we also focused on neutrophil activity for predicting the onset of SN.

The aim of this study was to investigate potential markers of $\mathrm{SN}$ in patients with advanced pancreatic or biliary tract cancer who received NAC(RT)-GS by evaluating clinicopathological variables and nutritional and immune markers (including $\mathrm{CI}_{\max }$ ) before $\mathrm{NAC}(\mathrm{RT})$.

\section{Materials and methods}

\section{Study population}

We conducted a retrospective observational study in the Department of Gastroenterological Surgery at Yokohama City University Graduate School of Medicine (Yokohama, Japan). The study protocol was approved by the Ethical Review Board of Yokohama City University Hospital (Yokohama, Japan) (approval number: 121101023). Sixty-four chemo-naïve patients with histologically proven advanced pancreatic or biliary tract cancer who were treated with NAC(RT)-GS between June 2013 and December 2015 were analyzed. Patients with multiple primary cancers and a history of prior chemotherapy, as well as those who did not complete NAC(RT)-GS, were excluded.

Pancreatic and biliary tract cancer was diagnosed and staged on the basis of ultrasonography, abdominal computed tomography, magnetic resonance imaging, ultrasound endoscopy, endoscopic retrograde cholangiopancreatography, positron emission tomography, cytological or histological examinations, and explorative laparotomy. NAC(RT) was administered to patients with borderline resectable pancreatic cancer as defined by National Comprehensive Cancer Network Guidelines Version 1/2012 [19].
NAC was administered to patients with biliary tract (hilar cholangiocarcinoma with arterial invasion, metastatic lymph nodes, or Bismuth type IV) or gallbladder cancer (plural metastatic lymph nodes or clinical T3-4 disease according to the tumor-node-metastasis classification of the International Union Against Cancer, 7th edition [20]).

\section{Neoadjuvant chemo(radio)therapy}

The NAC(RT) regimen for patients with pancreatic or biliary tract cancer consisted of gemcitabine $\left(1000 \mathrm{mg} / \mathrm{m}^{2}\right.$ administered intravenously on days 8 and 15) plus tegafur/ gimeracil/oteracil $\left(60 \mathrm{mg} / \mathrm{m}^{2}\right.$ administered orally on days $1-14)$. Patients with pancreatic cancer $(n=50)$ received two courses of GS followed by $30 \mathrm{~Gy}$ of radiation therapy. Patients with biliary tract cancer $(n=14)$ received three courses of GS.

\section{Evaluated factors}

Age, sex, body mass index, body surface area, Eastern Cooperative Oncology Group performance status, and a history of smoking, cardiovascular disease, and diabetes mellitus before receiving NAC(RT)-GS were evaluated from clinical records. $\mathrm{CI}_{\max }$, white blood cell count, ANC, lymphocyte count, platelet count, serum interleukin 6 level, C-reactive protein level, complement $\mathrm{C} 3$ titer, complement $\mathrm{C} 4$ titer, $50.0 \%$ hemolytic unit of complement, albumin level, prognostic nutritional index, serum carcinoembryonic antigen level, carbohydrate antigen 19-9 level, pancreatic cancer-associated antigen level, and s-pancreas-1 antigen level were also evaluated.

\section{Maximum chemiluminescence intensity}

$\mathrm{CI}_{\max }$ was assessed based on an in vitro reaction between peripheral neutrophils and endotoxin. An endotoxin activity assay was performed as described previously [21]. Fifty microliter samples of whole blood and appropriate controls were incubated in duplicate with saturating concentrations of an anti-lipid A immunoglobulin $\mathrm{M}$ antibody, and then stimulated with opsonized zymosan. The resulting respiratory burst was detected by a chemiluminometer (Autolumat LB953; Berthold Technologies GmbH \& Co. $\mathrm{KG}$, Bad Wildbad, Germany) as light released from the lumiphore luminol. The maximum stimulated response (termed as $\mathrm{CI}_{\max }$ by Kiguchi et al. [18]) was measured using lipopolysaccharide $(4.6 \mathrm{ng} / \mathrm{mL})$ as the stimulant. 


\section{Endpoints}

The primary endpoint was the incidence of Grade $\geq 3 \mathrm{SN}$ (ANC $<1000 / \mathrm{mL}$ ) during NAC(RT)-GS. The observation period was from the first to the last day of NAC(RT)-GS. The secondary endpoint was the RDI of gemcitabine.

\section{Statistical analyses}

Data are expressed as the median and range or number and percentage. Continuous variables were analyzed using the Mann-Whitney $U$ test and categorical variables were analyzed using Chi square or Fisher's exact test. Univariate and multivariate logistic regression analyses were performed to determine independent predictors of the incidence of SN during NAC(RT)-GS. Odds ratios and their $95.0 \%$ confidence intervals were calculated. Continuous variables were adjusted by dividing by the standard deviation and comparing to the odds ratio. Statistical analyses were conducted using Statistical Package for the Social Sciences for Windows (software version 23.0; SPSS Japan Inc., Tokyo, Japan). A $P<0.05$ was considered statistically significant.

\section{Results}

\section{Patient characteristics}

The patient characteristics are summarized in Table 1 . The median age was 71 (range 39-85) years. Thirty-six patients (56.3\%) were male. All patients had an Eastern Cooperative Oncology Group performance status of $0-1$. The general condition of the patients was satisfactory. Fifty patients (78.1\%) had advanced pancreatic cancer. Fourteen patients (21.9\%) had advanced biliary tract cancer. The median serum albumin levels were slightly lower, while the carbohydrate antigen 19-9 levels, pancreatic cancer-associated antigen levels, and s-pancreas-1 antigen levels were higher, than their normal ranges. SN was detected in 39 patients (60.9\%), within a median of 15 (range 10-36) days from commencing NAC(RT)-GS. All instances of SN occurred during the chemotherapy period and not the radiotherapy period.

\section{Univariate analysis}

The results of the univariate analysis are summarized in Table 2. $\mathrm{CI}_{\max }$, ANC, interleukin 6 level, C-reactive protein level, complement $\mathrm{C} 3$ titer, and $50.0 \%$ hemolytic unit of complement before NAC(RT) were identified as significant factors. Conversely, no epidemiological, tumor-related, or nutritional factors were found to be significant.
Table 1 Patient characteristics

\begin{tabular}{|c|c|}
\hline Characteristic & Patients $(n=64)$ \\
\hline Age (years), median (range) & $71(39-85)$ \\
\hline \multicolumn{2}{|l|}{ Sex, $n(\%)$} \\
\hline M & $36(56.2)$ \\
\hline $\mathrm{F}$ & $28(43.8)$ \\
\hline ECOG PS $(0-1), n(\%)$ & $64(100.0)$ \\
\hline BSA $\left(\mathrm{m}^{2}\right)$, median (range) & $1.6(1.1-1.9)$ \\
\hline BMI $\left(\mathrm{kg} / \mathrm{m}^{2}\right)$, median (range) & $21.0(14.3-29.8)$ \\
\hline \multicolumn{2}{|l|}{ Type of cancer, $n(\%)$} \\
\hline Pancreatic & $50(78.1)$ \\
\hline Biliary tract & $14(21.9)$ \\
\hline Smoking history, $n(\%)$ & $31(48.4)$ \\
\hline $\mathrm{CVD}, n(\%)$ & $8(12.5)$ \\
\hline $\mathrm{DM}, n(\%)$ & $26(40.6)$ \\
\hline Biliary drainage, $n(\%)$ & $29(45.3)$ \\
\hline WBC $(/ \mu \mathrm{L})$, median (range) & $5450(3200-10500)$ \\
\hline ANC $(/ \mu \mathrm{L})$, median (range) & $3349(1839-7603)$ \\
\hline $\mathrm{LC}(/ \mu \mathrm{L})$, median (range) & $1360(507-2789)$ \\
\hline $\mathrm{PC}\left(\times 10^{3} / \mu \mathrm{L}\right)$, median (range) & $19.4(10.7-33.3)$ \\
\hline $\mathrm{CI}_{\max }(\mathrm{RLU} / \mathrm{s})$, median (range) & $58,080(7371-521,141)$ \\
\hline $\mathrm{CI}_{\max } /$ neu, median (range) & $15.8(2.2-113.9)$ \\
\hline IL-6 (pg/mL), median (range) & $2.7(0.9-63.7)$ \\
\hline CRP (mg/dL), median (range) & $0.15(0.01-4.27)$ \\
\hline Serum albumin (g/dL), median (range) & $4.0(2.6-5.0)$ \\
\hline O-PNI, median (range) & $46.4(31.0-59.9)$ \\
\hline CEA (ng/mL), median (range) & $2.8(0.9-32.3)$ \\
\hline CA19-9 (U/mL), median (range) & $109.5(1.0-22,389.0)$ \\
\hline DUPAN-2 (U/mL), median (range) & $180.0(17.0-57,000.0)$ \\
\hline SPan-1 (U/mL), median (range) & $53.0(1.0-9700.0)$ \\
\hline
\end{tabular}

$A N C$ absolute neutrophil count, $B M I$ body mass index, $B S A$ body surface area, CA19-9 carbohydrate antigen 19-9, CEA carcinoembryonic antigen, $C I_{\max }$ maximum chemiluminescence intensity, $C R P$ c-reactive protein, $C V D$ cardiovascular disease, $D M$ diabetes mellitus, DUPAN-2 pancreatic cancer-associated antigen, ECOG Eastern Cooperative Oncology Group, $F$ female, $I L-6$ interleukin $6, L C$ lymphocyte count, $M$ male, $O$-PNI Onodera's prognostic nutritional index, $P C$ platelet count, $P S$ performance status, $R L U$ relative light unit, SPan-1 s-pancreas-1 antigen, WBC whole blood count

\section{Multivariate analysis}

The results of the multivariate analysis, which was performed using the six significant factors identified in the univariate analysis, are summarized in Table 3. Independent variables were selected using the simultaneous method for $\mathrm{CI}_{\max }$ and stepwise methods for the remaining five factors (the criterion for adding a new variable was $P<0.05$ ). $\mathrm{CI}_{\max }$ was identified as a significant independent predictor of $\mathrm{SN}$ during NAC(RT)-GS (odds ratio: $0.248,95.0 \%$ confidence interval 0.073-0.850; $P=0.026$ ). 
Table 2 Univariate analysis of factors predicting severe neutropenia $(\mathrm{SN})$ in patients with advanced pancreatic or biliary tract cancer

\begin{tabular}{|c|c|c|c|}
\hline \multirow[t]{2}{*}{ Factor } & \multicolumn{2}{|l|}{ Patients } & \multirow[t]{2}{*}{$P$ value } \\
\hline & $\mathrm{SN}(+)(n=39)$ & $\mathrm{SN}(-)(n=25)$ & \\
\hline Age (years), median (range) & $69(39-85)$ & $73(60-80)$ & 0.210 \\
\hline \multicolumn{4}{|l|}{ Sex, $n(\%)$} \\
\hline M & $20(51.3)$ & $16(64.0)$ & \\
\hline $\mathrm{F}$ & $19(48.7)$ & $9(36.0)$ & 0.229 \\
\hline BSA $\left(\mathrm{m}^{2}\right)$, median (range) & $1.6(1.1-1.9)$ & $1.6(1.2-1.9)$ & 0.923 \\
\hline BMI $\left(\mathrm{kg} / \mathrm{m}^{2}\right)$, median (range) & $21.4(16.4-29.8)$ & $20.8(14.3-27.5)$ & 0.591 \\
\hline \multicolumn{4}{|l|}{ Type of cancer, $n(\%)$} \\
\hline Pancreatic & $30(76.9)$ & $20(80.0)$ & \\
\hline Biliary tract & $9(23.1)$ & $5(20.0)$ & 0.513 \\
\hline Smoking history, $n(\%)$ & $20(51.3)$ & $11(44.0)$ & 0.378 \\
\hline CVD, $n(\%)$ & $3(7.7)$ & $5(20.0)$ & 0.144 \\
\hline $\mathrm{DM}, n(\%)$ & $14(35.9)$ & $12(48.0)$ & 0.241 \\
\hline Biliary drainage, $n(\%)$ & $15(38.5)$ & $14(56.0)$ & 0.204 \\
\hline WBC $(/ \mu \mathrm{L})$, median (range) & $5200(3200-8900)$ & $6200(4000-10,500)$ & 0.087 \\
\hline ANC $(/ \mu \mathrm{L})$, median (range) & 3197 (1839-7387) & $4222(2035-7603)$ & $0.017 *$ \\
\hline LC $(/ \mu \mathrm{L})$, median (range) & 1314 (506-2789) & $1,445(568-2415)$ & 0.778 \\
\hline $\mathrm{PC}\left(\times 10^{3} / \mu \mathrm{L}\right)$, median (range) & $18.1(11.6-33.3)$ & $21.0(10.7-30.9)$ & 0.299 \\
\hline $\mathrm{CI}_{\max }(\mathrm{RLU} / \mathrm{s})$, median (range) & $46,739(7370-156,539)$ & $70,041(34,831-521,140)$ & $0.006^{*}$ \\
\hline $\mathrm{CI}_{\max } / \mathrm{ANC}$, median (range) & $15.3(2.2-40.4)$ & $17.9(8.9-113.9)$ & 0.100 \\
\hline IL-6 (pg/mL), median (range) & $2.3(0.9-63.7)$ & $3.9(1.0-22.5)$ & $0.014 *$ \\
\hline CRP (mg/dL), median (range) & $0.11(0.01-2.27)$ & $0.39(0.01-4.27)$ & $0.028 *$ \\
\hline Serum C3 (mg/dL), median (range) & $105.0(74.0-139.0)$ & $113.0(79.0-177.0)$ & $0.018^{*}$ \\
\hline Serum C4 (mg/dL), median (range) & $28.0(15.0-43.0)$ & $28.0(13.0-42.0)$ & 0.534 \\
\hline CH50 (U/mL), median (range) & $46.1(31.5-61.5)$ & $52.4(36.3-91.8)$ & $0.011 *$ \\
\hline Serum albumin (g/dL), median (range) & $4.0(2.6-5.0)$ & $3.9(2.8-4.9)$ & 0.216 \\
\hline O-PNI, median (range) & $47.0(36.1-59.9)$ & $45.2(9.4-57.2)$ & 0.470 \\
\hline CEA (ng/mL), median (range) & $3.5(0.8-220.8)$ & $2.2(0.9-32.3)$ & 0.794 \\
\hline CA19-9 (U/mL), median (range) & $101.0(1.0-2,760.0)$ & $35.5(6.0-28,874.0)$ & 0.659 \\
\hline DUPAN-2 (U/mL), median (range) & $240.0(25.0-57,000.0)$ & $89.5(25.0-18,000.0)$ & 0.474 \\
\hline SPan-1 (U/mL), median (range) & $47.0(1.2-2000.0)$ & $21.0(3.3-21,000.0)$ & 0.620 \\
\hline S1 RDI (\%), median (range) & $100.0(30.0-100.0)$ & $100.0(33.0-100.0)$ & 0.249 \\
\hline GEM RDI (\%), median (range) & $65.0(30.0-100.0)$ & $75.0(33.0-100.0)$ & $0.035^{*}$ \\
\hline Cholangitis during NACRT, $n(\%)$ & $7(15.9)$ & $6(23.1)$ & 0.330 \\
\hline
\end{tabular}

(+) positive, (-) negative, $A N C$ absolute neutrophil count, BMI body mass index, BSA body surface area, C3 complement C3, C4 complement C4, CA19-9 carbohydrate antigen 19-9, CEA carcinoembryonic antigen, $C H 5050.0 \%$ hemolytic unit of complement, $C I_{\max }$ maximum chemiluminescence intensity, $C V D$ cardiovascular disease, $D M$ diabetes mellitus, DUPAN-2 pancreatic cancer-associated antigen, $F$ female, GEM gemcitabine, $I L-6$ interleukin 6, $L C$ lymphocyte count, $M$ male, NACRT neoadjuvant chemoradiotherapy, $O$ - $P N I$ Onodera's prognostic nutritional index, $P C$ platelet count, $R D I$ relative dose intensity, $R L U$ relative light unit, $S 1$ tegafur/gimeracil/oteracil, SPan-1 s-pancreas-1 antigen, $W B C$ white blood cell count $* P<0.05$

\section{Prediction ability}

The area under the receiver operating characteristic curve of the incidence of SN predicted by $\mathrm{CI}_{\max }$ was 0.704 (Fig. 1). The optimal threshold for the $\mathrm{CI}_{\max }$ was $46,000 \mathrm{RLU} / \mathrm{s}$. Applying this cutoff, the sensitivity and specificity were $46.2 \%$ and $80.0 \%$, respectively. The majority of patients $(n=18 ; 81.8 \%)$ with a low $\mathrm{CI}_{\max }$ before $\mathrm{NAC}(\mathrm{RT})$ experienced SN during NAC(RT)-GS.

\section{Relative dose intensity of gemcitabine}

The RDI of gemcitabine in patients with SN was lower than in those without SN (Table 2). At $\mathrm{CI}_{\max }$ cutoff of 46,000 RLU/s, the median RDI of gemcitabine was significantly 
Table 3 Multivariate analysis of factors predicting severe neutropenia in patients with advanced pancreatic or biliary tract cancer

\begin{tabular}{lllll}
\hline Factor & OR $(95.0 \%$ CI $)$ & $P$ value & OR $(95.0 \%$ CI $)$ & $P$ value \\
\hline CI $_{\max }$ (/SD) & $0.270(0.100-0.724)$ & $0.009^{*}$ & $0.248(0.073-0.850)$ & $0.026^{*}$ \\
ANC (/SD) & $0.517(0.291-0.916)$ & $0.024^{*}$ & - & - \\
$\mathrm{IL}-6$ (/SD) & $0.822(0.458-1.477)$ & 0.513 & - & - \\
$\mathrm{CRP}(/ \mathrm{SD})$ & $0.514(0.266-0.994)$ & $0.048^{*}$ & - & - \\
Serum C3 (/SD) & $0.738(0.461-1.183)$ & 0.207 & - & - \\
CH50 (/SD) & $0.662(0.396-1.105)$ & 0.114 & - & - \\
\hline
\end{tabular}

$A N C$ absolute neutrophil count, $\mathrm{C} 3$ complement $\mathrm{C} 3, \mathrm{CH} 5050.0 \%$ hemolytic unit of complement, $\mathrm{CI}$ confidence interval, $C I_{\max }$ maximum chemiluminescence intensity, $C R P$ c-reactive protein, $I L-6$ interleukin 6 , $O R$ odds ratio, $S D$ standard deviation

$* P<0.05$

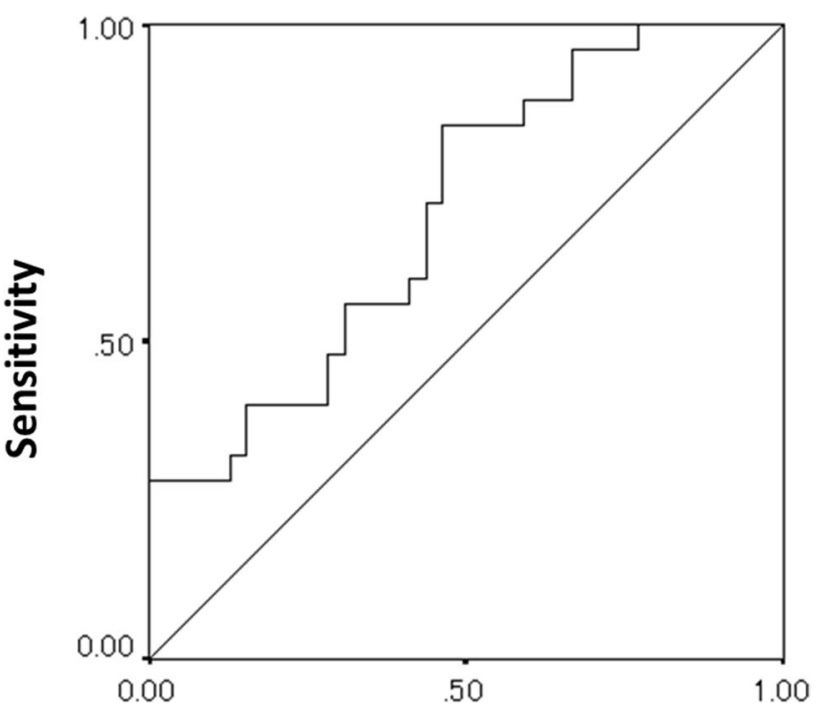

\section{1-Specificity}

Fig. 1 Receiver operating characteristic curve of the maximum chemiluminescence intensity for predicting severe neutropenia in patients with advanced pancreatic or biliary tract cancer

lower in the low $\mathrm{CI}_{\max }$ group than in the high $\mathrm{CI}_{\max }$ group (65.0\% vs. $75.0 \%$, respectively; $P=0.014$ ).

\section{Discussion}

Gemcitabine has a wide spectrum of anticancer activities with few non-hematological adverse events [22]. However, the GEST study [9] showed that SN had occurred in $62.2 \%$ of patients with locally advanced and metastatic pancreatic cancer in Japan and Taiwan. Consistent with the GEST study [9], the incidence of SN in our study was $60.9 \%$. Patients who develop SN during NAC require serial dose reductions until a tolerable dose is reached. In this study, the RDI of gemcitabine was significantly lower in patients who developed SN.

Studies [10-16] have shown epidemiological (age, sex, or a prior history), tumor-related, nutritional, and inflammatory statuses to be risk factors for SN. However, in relation to gemcitabine-based chemotherapy, risk factors for SN include a low ANC, a low white blood cell count, a low carbohydrate antigen 19-9 level, and no prior history of smoking $[17,23,24]$. In this study, no association was identified between epidemiological, tumor-related, or nutritional factors and the incidence of SN during NAC(RT)-GS.

In the present study, logistic regression analysis identified $\mathrm{CI}_{\max }$ before $\mathrm{NAC}(\mathrm{RT})$ as an independent predictor of $\mathrm{SN}$ during NAC(RT)-GS. At an optimal cutoff value of 46,000 $\mathrm{RLU} / \mathrm{s}$, the specificity of the $\mathrm{CI}_{\max }$ for predicting $\mathrm{SN}$ was $80.0 \%$. The positive predictive value was $81.8 \%$.

In patients with lipopolysaccharide-induced sepsis, the oxidative burst is significantly diminished in non-survivors compared to survivors [25]. Reduced oxidative activity may be associated with immune dysfunction and high mortality [25, 26]. Kiguchi et al. [18] reported that $\mathrm{CI}_{\max }$ before commencing treatment is indicative of the maximum neutrophil activity in whole blood and is highly predictive of mortality in patients with sepsis. $\mathrm{CI}_{\max }$ reflects neutrophil vitality or fatigue. Therefore, we hypothesized that $\mathrm{CI}_{\max }$ may be a predictor of SN during NAC.

In this study, univariate analysis identified a low $\mathrm{CI}_{\max }$, a low ANC, a low interleukin 6 level, a low C-reactive protein level, a low complement $\mathrm{C} 3$ titer, and a low $50.0 \%$ hemolytic unit of complement as risk factors for SN. In advanced cancer, chronic inflammation caused by an elevation in inflammatory cytokines leads to tumor progression [27], and activates neutrophil functions, such as the expression of adhesion molecules, phagocytosis, and the production of reactive oxygen species [28]. $\mathrm{CI}_{\max }$ reflects the reactive oxygen species production of neutrophils. Therefore, a low $\mathrm{CI}_{\max }$ indicates the inhibition of these inflammatory reactions. Recently, it has been reported [29, 30] that single 


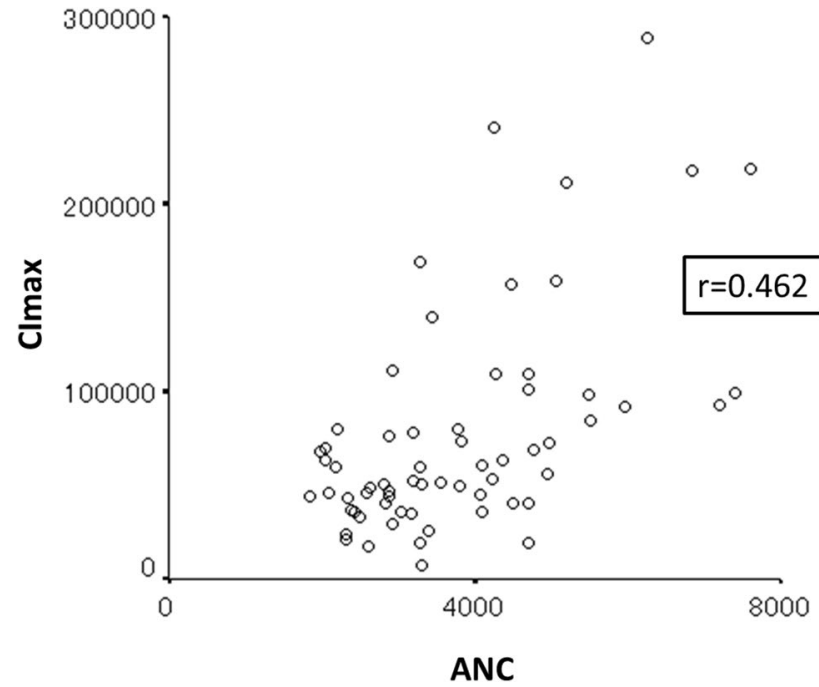

Fig. 2 Correlation between the maximum chemiluminescence intensity $\left(\mathrm{CI}_{\max }\right)$ and absolute neutrophil count (ANC)

nucleotide polymorphisms (SNPs) determine the individual components and/or the total white blood cell count. Furthermore, SNPs may correlate with the incidence of chemotherapy-induced neutropenia. Patients with SN may have a low baseline $\mathrm{CI}_{\max }$, resulting in the overall inhibition of inflammatory responses due to unknown SNPs, which result in lower neutrophil counts and reduced neutrophil activity. $\mathrm{CI}_{\max }$ may be a surrogate marker of not only predicting the incidence of SN, but also the patient's overall immune function.

Measurement of $\mathrm{CI}_{\max }$ is quick and convenient for clinical use. If $\mathrm{CI}_{\max }$ could be adopted in daily clinical practice then patients at risk of developing SN may be given prompt and appropriate treatment. Classifying patients into different risk groups based on their $\mathrm{CI}_{\max }$ may also help physicians choose the optimal treatment strategy. For instance, patients at a high risk of SN can be started with a reduced dose of GS and have their ANC strictly monitored by frequent blood tests. If patients are informed of their risk of neutropenia in advance, they can pay more attention to their own condition during treatment.

There is the potential that $\mathrm{SN}$ may arise exclusively from a low baseline ANC due to the inhibition of inflammation or neutrophil lowering SNPs. In other words, a low baseline ANC alone may be sufficient to cause to SN. However, we determined that the correlation coefficient between $\mathrm{CI}_{\max }$ and ANC was 0.462 (Fig. 2). Hence, $\mathrm{CI}_{\max }$ and $\mathrm{ANC}$ are independent factors. The multivariate analysis showed $\mathrm{CI}_{\max }$ to be a better predictive factor, representing the conclusive status of neutrophils.

$\mathrm{SN}$ is associated with the long-term prognosis of patients with various types of cancer, including breast [31,32], small cell lung [33, 34], gastric [35], colorectal [36, 37], ovarian
[38], and pancreatic $[39,40]$. The long-term prognosis may be associated with $\mathrm{SN}$ and $\mathrm{CI}_{\max }$, though this was not evaluated in this study. We are currently conducting a prospective cohort study focusing on the long-term outcomes of patients with advanced pancreatic cancer.

There are two limitations of this study. The first is that only a limited number of cases from a single institution were available at the time of conducting the study and the second is that only NAC(RT)-GS cases of advanced pancreatic or biliary tract cancer were analyzed. This paper only reports preliminary results. However, we believe that our findings are of interest. Multicenter studies involving greater number of patients with varying types of cancer and NAC regimens are needed to evaluate whether a low $\mathrm{CI}_{\max }$ is a useful marker for predicting SN.

In conclusion, our findings suggest that patients with advanced pancreatic or biliary tract cancer with a low $\mathrm{CI}_{\max }$ who are receiving $\mathrm{NAC}(\mathrm{RT})$ are at a high risk of developing SN during NAC(RT)-GS. Further studies with larger sample sizes are needed to validate our findings with other regimens (e.g., FOLFIRINOX and gemcitabine plus nanoparticle albumin-bound paclitaxel) and to confirm the associations between $\mathrm{CI}_{\max }, \mathrm{SN}$, SNPs, and long-term survival.

Funding This study was funded by Chugai Pharmaceutical Co., Ltd. and Yakult Honsha Co., Ltd.

\section{Compliance with ethical standards}

Conflict of interest The authors declare that they have no conflict of interest.

Ethical approval All procedures performed in studies involving human participants were in accordance with the ethical standards of the institutional and/or national research committee and with the 1964 Helsinki declaration and its later amendments or comparable ethical standards.

Informed consent Informed consent was obtained from all individual participants included in the study.

Open Access This article is distributed under the terms of the Creative Commons Attribution 4.0 International License (http://creativeco mmons.org/licenses/by/4.0/), which permits unrestricted use, distribution, and reproduction in any medium, provided you give appropriate credit to the original author(s) and the source, provide a link to the Creative Commons license, and indicate if changes were made.

\section{References}

1. Berlin J, Hoffman JP, Regine WF (2009) Editorial: combined modality treatment of resectable and borderline resectable pancreas cancer: expert consensus conference. Ann Surg Oncol 16:1757-1759. https://doi.org/10.1245/s10434-009-0412-x

2. Witzigmann H, Berr F, Ringel U, Caca K, Uhlmann D, Schoppmeyer K, Tannapfel A, Wittekind C, Mossner J, Hauss J, Wiedmann M (2006) Surgical and palliative management and outcome 
in 184 patients with hilar cholangiocarcinoma: palliative photodynamic therapy plus stenting is comparable to $\mathrm{r} 1 / \mathrm{r} 2$ resection. Ann Surg 244:230-239

3. Sho M, Akahori T, Tanaka T, Kinoshita S, Tamamoto T, Nomi T, Yamato I, Hokuto D, Yasuda S, Kawaguchi C, Nishiofuku H, Marugami N, Enomonoto Y, Kasai T, Hasegawa M, Kichikawa K, Nakajima Y (2013) Pathological and clinical impact of neoadjuvant chemo(radio)therapy using full-dose gemcitabine and concurrent radiation for resectable pancreatic cancer. J Hepatobiliary Pancreat Sci 20:197-205. https://doi.org/10.1007/s0053 4-012-0532-8

4. Kato A, Shimizu H, Ohtsuka M, Yoshidome H, Yoshitomi H, Furukawa K, Takeuchi D, Takayashiki T, Kimura F, Miyazaki M (2013) Surgical resection after downsizing chemotherapy for initially unresectable locally advanced biliary tract cancer: a retrospective single-center study. Ann Surg Oncol 20:318-324. https ://doi.org/10.1245/s10434-012-2312-8

5. Murakami Y, Uemura K, Sudo T, Hashimoto Y, Kondo N, Nakagawa N, Takahashi S, Sueda T (2017) Survival impact of neoadjuvant gemcitabine plus S-1 chemotherapy for patients with borderline resectable pancreatic carcinoma with arterial contact. Cancer Chemother Pharmacol 79:37-47. https://doi.org/10.1007/ s00280-016-3199-z

6. Walker EJ, Simko JP, Nakakura EK, Ko AH (2014) A patient with cholangiocarcinoma demonstrating pathologic complete response to chemotherapy: exploring the role of neoadjuvant therapy in biliary tract cancer. J Gastrointest Oncol 5:E88-E95. https://doi. org/10.3978/j.issn.2078-6891.2014.051

7. Kobayashi S, Tomokuni A, Gotoh K, Takahasi H, Akita H, Marubashi S, Yamada T, Teshima T, Fukui K, Fujiwara Y, Sakon M (2017) A retrospective analysis of the clinical effects of neoadjuvant combination therapy with full-dose gemcitabine and radiation therapy in patients with biliary tract cancer. Eur J Surg Oncol 43:763-771. https://doi.org/10.1016/j.ejso.2016.12.008

8. The Japanease Clinical Oncology Group. Japanease version of the Common Terminology Criteria for Adverse Events version 4.0. http://ganjoho.jp/reg_stat/index.html

9. Ueno H, Ioka T, Ikeda M, Ohkawa S, Yanagimoto H, Boku N, Fukutomi A, Sugimori K, Baba H, Yamao K, Shimamura T, Sho M, Kitano M, Cheng AL, Mizumoto K, Chen JS, Furuse J, Funakoshi A, Hatori T, Yamaguchi T, Egawa S, Sato A, Ohashi Y, Okusaka T, Tanaka M (2013) Randomized phase III study of gemcitabine plus S-1, S-1 alone, or gemcitabine alone in patients with locally advanced and metastatic pancreatic cancer in Japan and Taiwan: GEST study. J Clin Oncol 31:1640-1648. https://doi. org/10.1200/JCO.2012.43.3680

10. Lyman GH, Morrison VA, Dale DC, Crawford J, Delgado DJ, Fridman M, OPPS Working Group; ANC Study Group (2003) Risk of febrile neutropenia among patients with intermediategrade non-Hodgkin's lymphoma receiving CHOP chemotherapy. Leuk Lymphoma 44:2069-2076

11. Aslani A, Smith RC, Allen BJ, Pavlakis N, Levi JA (2000) The predictive value of body protein for chemotherapy-induced toxicity. Cancer 88:796-803

12. Watanabe H, Ikesue H, Oshiro M, Nagata K, Mishima K, Takada A, Suetsugu K, Sueyasu M, Egashira N, Harada T, Takayama K, Nakanishi Y, Oishi R (2012) Risk factors for predicting severe neutropenia induced by amrubicin in patients with advanced lung cancer. Chemotherapy 58:419-425. https://doi.org/10.1159/00034 5617

13. Alexandre J, Gross-Goupil M, Falissard B, Nguyen ML, Gornet JM, Misset JL, Goldwasser F (2003) Evaluation of the nutritional and inflammatory status in cancer patients for the risk assessment of severe haematological toxicity following chemotherapy. Ann Oncol 14:36-41
14. Tang NL, Liao CD, Wang X, Mo FK, Chan VT, Ng R, Pang E, Suen JJ, Woo J, Yeo W (2013) Role of pharmacogenetics on adjuvant chemotherapy-induced neutropenia in Chinese breast cancer patients. J Cancer Res Clin Oncol 139:419-427. https:// doi.org/10.1007/s00432-012-1345-5

15. Moreau M, Klastersky J, Schwarzbold A, Muanza F, Georgala A, Aoun M, Loizidou A, Barette M, Costantini S, Delmelle M, Dubreucq L, Vekemans M, Ferrant A, Bron D, Paesmans M (2009) A general chemotherapy myelotoxicity score to predict febrile neutropenia in hematological malignancies. Ann Oncol 20:513-519. https://doi.org/10.1093/annonc/mdn655

16. Chia VM, Page JH, Rodriguez R, Yang SJ, Huynh J, Chao C (2013) Chronic comorbid conditions associated with risk of febrile neutropenia in breast cancer patients treated with chemotherapy. Breast Cancer Res Treat 138:621-631. https://doi. org/10.1007/s10549-013-2454-9

17. Kanai M, Morita S, Matsumoto S, Nishimura T, Hatano E, Yazumi S, Sasaki T, Yasuda H, Kitano T, Misawa A, Ishiguro H, Yanagihara K, Ikai I, Doi R, Fukushima M (2009) A history of smoking is inversely correlated with the incidence of gemcitabine-induced neutropenia. Ann Oncol 20:1397-1401. https://doi.org/10.1093/annonc/mdp008

18. Kiguchi T, Nakamori Y, Yamakawa K, Kitayama J, Wada D, Ogawa Y, Ogura H, Kuwagata Y, Shimazu T, Hamasaki T, Fujimi S (2013) Maximal chemiluminescent intensity in response to lipopolysaccharide assessed by endotoxin activity assay on admission day predicts mortality in patients with sepsis. Crit Care Med 41:1443-1449. https://doi.org/10.1097/ CCM.0b013e31827ca960

19. National Comprehensive Cancer Network (NCCN) (2012) Clinical practice guidelines in oncology. Pancreatic adenocarcinoma. Version 1. https://www.nccn.org/professionals/physician_gls/pdf/ pancreatic.pdf

20. Sobin LH, Gospodarowicz MK, Wittekind C (2009) TNM classification of malignant tumours, 7th edn. Wiley-Blackwell, Chichester

21. Sato M, Matsuyama R, Kadokura T, Mori R, Kumamoto T, Nojiri K, Taniguchi K, Takeda K, Kubota K, Tanaka K, Endo I (2014) Severity and prognostic assessment of the endotoxin activity assay in biliary tract infection. J Hepatobiliary Pancreat Sci 21:120-127. https://doi.org/10.1002/jhbp

22. Burris HA 3rd, Moore MJ, Andersen J, Green MR, Rothenberg ML, Modiano MR, Cripps MC, Portenoy RK, Storniolo AM, Tarassoff P, Nelson R, Dorr FA, Stephens CD, Von Hoff DD (1997) Improvements in survival and clinical benefit with gemcitabine as first-line therapy for patients with advanced pancreas cancer: a randomized trial. J Clin Oncol 15:2403-2413

23. O'Malley M, Healy P, Daignault S, Ramnath N (2013) Cigarette smoking and gemcitabine-induced neutropenia in advanced solid tumors. Oncology 85:216-222. https://doi.org/10.1159/00035 5107

24. Yoneyama K, Katsumoto E, Kurihara T, Kogo M, Ikegami A, Imawari M, Shimada K, Yoshikumi H, Inoue K, Kiuchi Y (2012) Factors predicting the appearance of neutropenia in patients with advanced pancreatic cancer undergoing gemcitabine therapy. Hepatogastroenterology 59:894-898. https://doi.org/10.5754/ hge 11567

25. Martins PS, Kallas EG, Neto MC, Dalboni MA, Blecher S, Salomão R (2003) Upregulation of reactive oxygen species generation and phagocytosis, and increased apoptosis in human neutrophils during severe sepsis and septic shock. Shock 20:208-212

26. Hsu HY, Wen MH (2002) Lipopolysaccharide-mediated reactive oxygen species and signal transduction in the regulation of interleukin-1 gene expression. J Biol Chem 277:22131-22139

27. Coussens LM, Werb Z (2002) Inflammation and cancer. Nature 420:860-867 
28. Bekes EM, Schweighofer B, Kupriyanova TA, Zajac E, Ardi VC, Quigley JP, Deryugina EI (2011) Tumor-recruited neutrophils and neutrophil TIMP-free MMP-9 regulate coordinately the levels of tumor angiogenesis and efficiency of malignant cell intravasation. Am J Pathol 179:1455-1470. https://doi.org/10.1016/j.ajpat h.2011.05.031

29. Sugishita M, Imai T, Kikumori T, Mitsuma A, Shimokata T, Shibata T, Morita S, Inada-Inoue M, Sawaki M, Hasegawa Y, Ando Y (2016) Pharmacogenetic association between GSTP1 genetic polymorphism and febrile neutropenia in Japanese patients with early breast cancer. Breast Cancer 23:195-201. https://doi.org/10.1007/ s12282-014-0547-x

30. Uchiyama T, Kanno H, Ishitani K, Fujii H, Ohta H, Matsui H et al (2012) An SNP in CYP39A1 is associated with severe neutropenia induced by docetaxel. Cancer Chemother Pharmacol 69:1617-1624

31. Saarto T, Blomqvist C, Rissanen P, Auvinen A, Elomaa I (1997) Haematological toxicity: a marker of adjuvant chemotherapy efficacy in stage II and III breast cancer. Br J Cancer 75:301-305

32. Cameron DA, Massie C, Kerr G, Leonard RC (2003) Moderate neutropenia with adjuvant CMF confers improved survival in early breast cancer. Br J Cancer 89:1837-1842

33. Di Maio M, Gridelli C, Gallo C, Shepherd F, Piantedosi FV, Cigolari S, Manzione L, Illiano A, Barbera S, Robbiati SF, Frontini L, Piazza E, Ianniello GP, Veltri E, Castiglione F, Rosetti F, Gebbia V, Seymour L, Chiodini P, Perrone F (2005) Chemotherapyinduced neutropenia and treatment efficacy in advanced nonsmall-cell lung cancer: a pooled analysis of three randomised trials. Lancet Oncol 6:669-677

34. Pallis AG, Agelaki S, Kakolyris S, Kotsakis A, Kalykaki A, Vardakis N, Papakotoulas P, Agelidou A, Geroyianni A, Agelidou M, Hatzidaki D, Mavroudis D, Georgoulias V, Hellenic Oncology
Research Group (HORG) (2008) Chemotherapy-induced neutropenia as a prognostic factor in patients with advanced nonsmall cell lung cancer treated with front-line docetaxel-gemcitabine chemotherapy. Lung Cancer 62:356-363. https://doi. org/10.1016/j.lungcan.2008.03.030

35. Yamanaka T, Matsumoto S, Teramukai S, Ishiwata R, Nagai Y, Fukushima M (2007) Predictive value of chemotherapy-induced neutropenia for the efficacy of oral fluoropyrimidine S-1 in advanced gastric carcinoma. Br J Cancer 97:37-42

36. Shitara K, Matsuo K, Takahari D, Yokota T, Inaba Y, Yamaura H, Sato Y, Najima M, Ura T, Muro K (2009) Neutropaenia as a prognostic factor in metastatic colorectal cancer patients undergoing chemotherapy with first-line FOLFOX. Eur J Cancer 45:17571763. https://doi.org/10.1016/j.ejca.2009.01.019

37. Sunaga T, Suzuki S, Kogo M, Kurihara T, Kaji S, Koike N, Harada N, Suzuki M, Kiuchi Y (2014) The association between neutropenia and prognosis in stage III colorectal cancer patients receiving adjuvant chemotherapy. Eur J Cancer Care (Engl) 23:394-400. https://doi.org/10.1111/ecc.12120

38. Rocconi RP, Matthews KS, Kemper MK, Hoskins KE, Barnes MN (2008) Chemotherapy-related myelosuppression as a marker of survival in epithelial ovarian cancer patients. Gynecol Oncol 108:336-341

39. Ikagawa M, Kimura M, Iwai M, Usami E, Yoshimura T, Yasuda K (2016) Neutropenia as a prognostic factor and safety of secondline therapy with S-1 for advanced or recurrent pancreatic cancer. Mol Clin Oncol 5:283-288

40. Kurihara T, Kogo M, Ishii M, Shimada K, Yoneyama K, Kitamura K, Shimizu S, Yoshida H, Kiuchi Y (2015) Chemotherapy-induced neutropenia as a prognostic factor in patients with unresectable pancreatic cancer. Cancer Chemother Pharmacol 76:1217-1224. https://doi.org/10.1007/s00280-015-2887-4 